\title{
Evaluation of the Microclinic Social Network Model for Palestine Refugees with Diabetes at UNRWA Health Centers
}

\author{
Yousef M. Shahin1, Nada Abu Kishk1, Yassir Turki', Suha Saleh"1, Eric L. Ding', \\ Daniel E. Zoughbie ${ }^{2}$, Akihiro Seita ${ }^{1}$ \\ ${ }^{1}$ United Nations Relief and Works Agency for Palestine Refugees in the Near East, Amman, Jordan \\ ${ }^{2}$ Microclinic International, San Francisco, USA \\ ${ }^{3}$ Harvard Chan School of Public Health, Department of Nutrition, Boston, USA \\ Email: y.shahin2@unrwa.org
}

How to cite this paper: Shahin, Y.M., Kishk, N.A., Turki, Y., Saleh, S., Ding, E.L., Zoughbie, D.E. and Seita, A. (2018) Evaluation of the Microclinic Social Network Model for Palestine Refugees with Diabetes at UNRWA Health Centers. Journal of Diabetes Mellitus, 8, 99-113.

https://doi.org/10.4236/jdm.2018.84010

Received: July 11, 2018

Accepted: September 10, 2018

Published: September 13, 2018

Copyright $\odot 2018$ by authors and Scientific Research Publishing Inc. This work is licensed under the Creative Commons Attribution International License (CC BY 4.0).

http://creativecommons.org/licenses/by/4.0/

\begin{abstract}
Background: UNRWA provides primary healthcare for around 5.9 million Palestine refugees (PRs) in Jordan, Lebanon, Syria, West Bank and Gaza. In 2015, UNRWA started, in cooperation with Microclinic International (MCI), to implement an innovative diabetes program, aiming at improving awareness about diabetes care among PRs with Diabetes Mellitus (DM). This program takes advantage of a unique model of "microclinic" MCI social network program, a novel social network based on diabetes education intervention. Methods: A quasi-experimental study was conducted to evaluate the impact of the UNRWA-MCI program in 115 UNRWA's HCs in Jordan, Lebanon, West Bank and Gaza. 1000 participants were randomly selected from around 60,000 participants in the program. After training 996 nurses on UNRWA-MCI diabetes care modules, groups of 10 - 15 participants with their social networks (around 20 participants in each group) attended eight weekly sessions, during which the program was introduced. Anthropometric and blood pressure (BP) measurements were collected on weekly basis, while glycated hemoglobin (HbAlc) was tested before involvement in the program and after completion of sessions with a three month period between both measurements. SPSS Version 22 was used for data analysis. The study protocol was reviewed and cleared by UNRWA, Health Department ethical committee. Results: Out of 1000 patients randomly selected for the evaluation of the impact of the program, 969 (81.9\% females, $18.1 \%$ males) have completed the study. The average weight loss was $2.0 \pm 4.6 \mathrm{Kg}$ and significant improvements were seen in waist circumference (WC), $\mathrm{HbAlc}$ and $\mathrm{BP}$ ( $\mathrm{p} \leq 0.001$ for all). Overall drop in $\mathrm{HbAlc}$ was $0.6 \pm 1.2$ with $8.5 \%$ increase in patients with
\end{abstract}


HbAlc $<7.0$ and $9.8 \%$ decrease in those with HbAlc $\geq 7.0$. About $10.0 \%$ of patients with abnormal BP (higher than $140 / 90 \mathrm{mg} / \mathrm{dl}$ based on UNRWA's criteria for BP of diabetics) had shifted to normal BP. Conclusions and Recommendations: UNRWA-MCI program improved anthropometric measurements, $\mathrm{HbAlc}$ and $\mathrm{BP}$ in diabetic PRs. It improved diabetes care management for PRs, and led to the involvement of their social networks to support their behavior change for a healthy lifestyle.

\section{Keywords}

UNRWA, Microclinic International, Diabetes Care, Education, HbA1c

\section{Introduction}

Conflict and natural disasters have forcibly displaced more people than ever before; thus, creating effective strategies to address health needs of displaced populations have become a key global health priority [1] [2] [3]. Palestine refugees represent the largest refugee population in the world; currently over 5.9 million Palestine refugees are registered with the United Nations Relief and Works Agency for Palestine Refugees in the Near East (UNRWA), and over $30.0 \%$ of them live in camps in the five fields of operations, including West Bank, Jordan, Lebanon, the Gaza Strip and Syria. Mandated by the UN General Assembly in late 1949, UNRWA started its operations to provide humanitarian assistance and protection to the registered Palestine refugees in the five fields. Funded almost entirely by voluntary contributions by different donors, UNRWA's human development and humanitarian services encompass education, primary health care, relief and social services, infrastructure and camp improvement, and emergency response in situations of armed conflict. UNRWA is the main primary healthcare provider for Palestine refugees [4] [5].

As in many countries across the world, non-communicable diseases (NCDs) have emerged as the main cause of mortality among refugee populations [2] [6]; cardiovascular disease, hypertension, cancer and diabetes are now the main causes of morbidity and mortality accounting for more than $70.0 \%$ of deaths among Palestine refugees [6]-[11]. By the end of 2016, UNRWA records showed that over 140 thousand people in Palestine refugee camps have type 2 diabetes (DMII), and that around 4000 of them live with type 1 diabetes. Diabetes is a growing problem among refugees as among others-the number of Palestine refugees diagnosed with diabetes is estimated to grow by $3 \%-5 \%$ annually [12].

UNRWA conducted 2 rounds of Clinical Audits on Diabetes care in Jordan, Lebanon, West Bank and Gaza with a sample size of 1600 diabetic patients. The first audit was conducted in 2012 followed by second round in 2015 using same methodology. The results of both audits revealed that there is a need for comprehensive and standardized training materials to be used by health staff across all fields, in addition to the need for capacity building of staff and for raising 
awareness among patients on the management of the disease and the avoidance of its complications, and raising the awareness of community members about the risks that lead to the development diabetes and the importance of a healthy life style practices. Microclinic approach was adapted and implemented accordingly [8] [13].

Healthcare in a refugee camp setting is particularly challenging. Refugee camps often have even greater barriers to care than other settings in the developing world [6] [14]; camps often have poor infrastructure, such as poor road accessibility and limited power supplies [15] [16]. Furthermore, they tend to have limited resources and a fast growing population, which create food and clean water shortages [6] [14] [15] [16]. Additionally, with the transient nature of the camps, it is often difficult to provide sustained health care over time, which is a key component of effective NCD treatment and prevention. Moreover, NCDs in particular are costly and complicated conditions to treat, often driven by lifestyle and unhealthy behaviors such as poor diets, physical inactivity, smoking and obesity [14].

Previous studies show that social networks can be harnessed to impact people's health behavior. Since diabetes is a chronic disease which requires extensive behavioral changes and adherence to a complex diet and healthy behaviours, social support is considered as one of the influential and important factors for performing self-care and for adherence to the treatment and disease control [17]. Microclinic International (MCI) is a non-governmental organization that aims to improve NCD self-care and management using a social network-based health education program named the Microclinic Social Network (MSN) model. The MCI strategy builds on the idea that lifestyle behaviors spread from one individual to another within their social networks. A "Microclinic" is a human network consisting of small groups of people, who together receive health education and participate in activities that promote healthy lifestyle changes. The model hopes that these groups would bring the lessons they learn to the rest of their social network members, and that the newly acquired healthy habits would spread throughout the community. Furthermore, this model involves identifying local community partners, and training them on the MSN model, so that participants learn from members of their own community who understand the local needs and customs [18] [19].

This program aimed to improve diabetes education and self-management and to empower patients through the novel Microclinic education intervention involving patients and their social networks. The MSN framework has proven effective around the world [17]-[22]. Previous studies evaluating the Microclinic diabetes education program showed a reduction in diabetes related risk factors and an improvement in healthy behaviors within various communities in the United States, Kenya, Palestine, and Jordan [18] [19] [20] [21].

In June 2015, the UNRWA and MCI partnered to bring the MSN program to 115 UNRWA health centers (HCs) in Jordan, Lebanon, West Bank and Gaza 
aiming to:

1) Improving the level of awareness about diabetes care and self-management among Palestine refugees with DM; and

2) Building the capacity of UNRWA healthcare providers to better deliver diabetes care and management to PR diabetic patients attending UNRWA HCs.

This study was conducted to evaluate the UNRWA-MCI joint effort and partnership to deliver the MSN program to Palestine refuges with DM in UNRWA's HCs.

\section{Methodology}

\subsection{Study Design}

A quasi-experimental design was used in this study to compare pre-intervention and post-intervention measurements without a control group (one-group pretest-posttest design). This is because our aim was to demonstrate the potential relationship between the intervention (MSN model) and the aimed outcomes.

\subsection{Population and Setting}

\subsubsection{Inclusion \& Exclusion Criteria}

Inclusion criteria: Patients attending selected UNRWA HCs with confirmed DM condition based on the UNRWA adopted diagnostic criteria which states that in order to establish the diagnosis of diabetes or otherwise, patients should have a fasting blood sugar level (FPG) falling between $100-125 \mathrm{mg} / \mathrm{dl}$ and are required to perform another FPG test within a week. If the value is still between $100-125 \mathrm{mg} / \mathrm{dl}$, then a glucose tolerance test (OGTT) should be performed using a load containing the equivalent of 75 gms of oral anhydrous glucose solution. Diabetes is diagnosed if plasma glucose is evaluated to be $\geq 200 \mathrm{mg} / \mathrm{dl}$ two hours after the challenge. Moreover, the cut-off value for confirmation of diagnosis of diabetes is a FPG level $>126 \mathrm{mg} / \mathrm{dl}$ on at least two consecutive tests within one week [8] [23].

Participants gave verbal informed consent, and they expressed their commitment to participate in all the planned education sessions and measurements.

Exclusion criteria: Non-Palestine refugees with DM and/or Palestine refugees who are not registered at UNRWA health centers were excluded.

\subsubsection{Sampling}

Over two years, about 60,000 Palestine refugees with DM have participated in the UNRWA-MCI program in groups (Microclinics) each of 10 - 15 patients. For over an average of 19 weeks, each group attended eight educational sessions about diabetes care and management using 8 modules that were adapted from the MSN framework. Late in 2017, a sample of 1000 patients; 250 from each of the four participating fields, who were involved in the MCI sessions were randomly selected to participate in the evaluation of the impact of the UNRWA-MCI program. 


\subsection{Program \& Study Procedures}

A Total of 32 Nurses (8 from each Field) were offered a three-day training-of-trainers (ToT) workshop on the curriculum. The training workshops included the introduction of the concept of MCI which says that "health is contagious" and the concept of $4 \mathrm{Ms}$ (meals-having healthy diets, movement-being physically active, medicines-taking medicines as prescribed and measurements-measuring sugar regularly at home). This has been done through a series of eight sessions using interactive and systematically constructed PowerPoint presentations that are supported by a facilitator's guide and a set of tools, health education videos and relevant comics. In addition, the participants were trained on communication and counselling skills. All the materials were presented in Arabic and were adapted for the use in the cultural context in the five Fields. Afterwards, each trained nurse conducted a series of training workshops on the program for all the other nurses in all HCs over the following 12 months.

In total, 996 nurses were trained on the eight MSN modules and have recruited eligible DM patients at their HCs to deliver the modules to them. Groups of 10 - 15 DM patients were formed and requested to attend the eight DM educational sessions where the MSN program was introduced. Each patient was requested to invite their social network members; such as friends, family members and neighbors making each group's size around 20 participants. For each group, the leading nurse conducted a series of 8 diabetes education sessions over 19 weeks. Sessions were scheduled once every week or two weeks depending on the health center's circumstances (availability of staff, place, space and other factors). They took place at the health center or at a nearby facility. Each session lasted for 1 - 2 hours and covered one module followed by 20 minutes of light physical exercise. After finishing seven sessions, typically in seven weeks, participants were asked to apply what they have learnt over the next two months (8 weeks), then to join the last $8^{\text {th }}$ session on week 19 for graduation and evaluation of the program.

The measurements of body weight, waist circumference (WC), blood pressure (BP) were taken for the 1000 patients in each session in an excel file, while $\mathrm{HbAlc}$ was checked in the first session and at the end of the last session; i.e. within a minimum interval of 3 months between both. Height was measured once at the start of the program.

The major components of the curriculum included: 1) health education to promote knowledge about diabetes prevention and treatment; 2) promotion of social network support through improving the skills of participants about their disease management, healthy lifestyles practices, and self-monitoring techniques; 3) the preparation of trained UNRWA-MCI ambassadors who convey what they learn to their social network and community members; and 4) conducting moderate physical activity exercises for 20 minutes in each session.

The study was approved by UNRWA's Health Department and the legal office at UNRWA. 


\subsection{Data Entry and Analysis}

As was mentioned before, data was entered into excel work sheet; participants with missing baseline data, or who had inconsistent values between the variables; for instance, height or waist circumference measure was not consistent with the other readings for the same participant, were excluded. Statistical analysis was performed using Statistical Package for the Social Sciences (SPSS) software version 22. A descriptive analysis for the quantitative variables (presented as mean and standard deviation) and for qualitative variables (presented as frequencies and percentages) was conducted. Categorization of the results for certain variables was done; such as overall obesity using Body Mass Index (BMI). BMI was calculated in kilograms per meter squared and readings for the participants were categorized as follows: underweight, $\mathrm{BMI}<18.5$, normal weight, $18.5 \leq \mathrm{BMI}<$ 25 ; overweight, $25 \leq \mathrm{BMI}<30$; obesity class I, $30 \leq \mathrm{BMI}<35$; obesity class II, 35 $\leq \mathrm{BMI}<40$; and, extreme obesity (class III), BMI $\geq 40$ [22]. Abdominal obesity was assessed using waist circumference. Participants were considered to be at risk due to abdominal obesity if men's WC measurements were $>102 \mathrm{~cm}$, and if women's WC measurements were $>88 \mathrm{~cm}$ [22]. Blood pressure readings of the participants were classified into the following categories: readings were considered not at risk if systolic BP was $<140 \mathrm{mmHg}$ and diastolic BP was $<90$ $\mathrm{mmHg}$, whereas readings were classified as at risk when systolic BP was $\geq 140$ $\mathrm{mmHg}$ and diastolic BP was $\geq 90 \mathrm{mmHg}$ [24]. Glycemic control was assessed using participants' $\mathrm{HbAlc}$ measurements. Patients were considered as uncontrolled if their $\mathrm{HbAlc}$ is $\geq 7.0 \%$ and as controlled if their $\mathrm{HbAlc}$ is $<7.0 \%$ [8] [25]. We compared mean weight, BMI, waist circumference, blood pressure, and $\mathrm{HbAlc}$ readings before and after the intervention using paired t-tests. Furthermore, McNemar and McNemar-Bowker tests were used to show the shifting of the participants' readings within each of the mentioned categories before and after the intervention. The differences in measurements before and after the intervention were considered to be statistically significant if $\mathrm{p} \leq 0.05$.

\section{Results}

\subsection{Patient Demographics}

Out of the 1000 participants randomly selected for the evaluation, 31 who had some missing or inconsistent data were excluded from the consequent analysis. The average age of the 969 patients included in the data analysis was $54.2 \pm 11.7$ years, including 795 females (82.0\%) and 174 males (18.0\%). Table 1 shows the number and proportion of patients who participated in the evaluation process stratified by field.

\subsection{Body Measurements and Biomarkers}

Average of body weight, waist circumference, blood pressure and HbAlc values taken in session 1 and in session 8 separated by an average period of 19 weeks; 
Table 1. Number and proportion of patients who participated in the evaluation process stratified by field.

\begin{tabular}{cc}
\hline Field & Number \& percentage \\
\hline Jordan & $207(21.4 \%)$ \\
Lebanon & $234(24.1 \%)$ \\
Gaza & $243(25.1 \%)$ \\
West Bank & $285(29.4 \%)$ \\
Total & $969(100 \%)$ \\
\hline
\end{tabular}

there were significant reduction ( $\mathrm{p}<0.001$ for each) in the averages of the mentioned categories, as shown in Table 2.

In average, participants have lost $1.9 \pm 2.6 \mathrm{Kg}$ of their weight; $7.2 \%$ had lost more than $7.0 \%$ of their weight, and $65 \%$ lost between $0.0 \%$ and less than $7.0 \%$ of their weight, whereas $27.8 \%$ had gained or had no change in their weight.

A significant reduction in the average BMI of the participants was observed after the program (32.6 \pm 5.9 before and $31.9 \pm 5.8$ after) (Table 2). Table 3 shows the percentage of change in all BMI categories before and after the program for both genders. It was observed that there was shifting in the total number of patients between the different BMI categories. For example, the number of obese participants has been reduced in obesity class II category (from 207 to 170) and in extreme obesity category (class III) (from 93 to 80), whereas the numbers in the normal and overweight BMI categories have been increased, which might explain the shift in numbers for obesity class II and extreme obesity (class III) categories.

Based on the WC data for the 969 patients, the average of the WC measurement was found to be significantly reduced by $1.7 \mathrm{~cm}(103.6 \pm 15.3$ to $101.9 \pm$ 14.7) (Table 2). According to the World Health Organization (WHO), a waist circumference of $>102 \mathrm{~cm}$ in men, or $>88 \mathrm{~cm}$ in women, has a substantially increased risk of health problems such as diabetes type 2, heart disease and high blood pressure [22]. Based on that, the WC has been stratified in both genders according to their WC high risk cut-off points and then the overall change in WC for all participants has been examined. Table 4 shows the numbers of patients of the two genders stratified based on the risk they have due to their WC measurements before and after the program. The number of participants who had risky WC measurements decreased at the end of the program.

We have also examined the changes in the $\mathrm{BP}$ readings for the participants before and after the program. In general, there was a significant reduction in the averages of the BP readings including both systolic and diastolic values. At the beginning of the program the average BP for the 969 participants was $129.3 \pm$ $15.6 / 79.2 \pm 8.5 \mathrm{mmHg}$, while at the end of the program it was $125.3 \pm 13.5 / 76.9$ $\pm 7.8 \mathrm{mmHg}$ (Table 2). A blood pressure (BP) equal or higher than $140 / 90$ $\mathrm{mmHg}$ is linked to an increased risk of heart disease and stroke [23]. Based on that, the significance of the change in the average BP values were compared to 
Table 2. Body measurements and biomarkers from baseline (session 1 at week 1) to the end of the program (session 8 at week 19).

\begin{tabular}{cccccc}
\hline Parameters & $\begin{array}{c}\text { Session } 1 \text { at } \\
\text { week 1 }\end{array}$ & $\begin{array}{c}\text { Session } 8 \text { at } \\
\text { week 19 }\end{array}$ & $\begin{array}{c}\text { Average } \\
\text { change }\end{array}$ & $\begin{array}{c}\text { 95\% Confidence } \\
\text { Interval }\end{array}$ & P Value $^{*}$ \\
\hline Weight $(\mathrm{Kg})$ & $83.6 \pm 16.4$ & $81.8 \pm 15.9$ & $-1.9 \pm 2.6$ & $1.7-2.0$ & $<0.001$ \\
BMI (Kg/m²) & $32.6 \pm 5.9$ & $31.9 \pm 5.8$ & $-0.7 \pm 1.0$ & $0.7-0.8$ & $<0.001$ \\
Waist circumference (cm) & $103.6 \pm 15.3$ & $101.9 \pm 14.7$ & $-1.7 \pm 3.3$ & $1.5-1.9$ & $<0.001$ \\
$\begin{array}{c}\text { Systolic blood pressure } \\
\text { (mmHg) }\end{array}$ & $129.3 \pm 15.6$ & $125.3 \pm 13.5$ & $-4.0 \pm 13.0$ & $3.2-4.8$ & $<0.001$ \\
$\begin{array}{c}\text { Diastolic blood } \\
\text { pressure (mmHg) }\end{array}$ & $79.2 \pm 8.5$ & $76.9 \pm 8.0$ & $-2.3 \pm 8.5$ & $1.7-2.8$ & $<0.001$ \\
HbAlc (\%) & $8.5 \pm 1.9$ & $7.9 \pm 1.8$ & $-0.6 \pm 1.2$ & $0.5-0.6$ & $<0.001$ \\
\hline
\end{tabular}

${ }^{*}$ Paired t-test was applied.

Table 3. Numbers of patients in each of the BMI categories before and after the program.

\begin{tabular}{cccc}
\hline BMI categories & $\begin{array}{c}\text { Session 1 } \\
\text { No. \& (\%) }\end{array}$ & $\begin{array}{c}\text { Session 8 } \\
\text { No. \& }(\%)\end{array}$ & $\begin{array}{c}\text { Change } \\
\text { No. \& (\%) }\end{array}$ \\
\hline Underweight $(<18.5)$ & $4(0.4 \%)$ & $5(0.5 \%)$ & +1 \\
Normal $(18.5-24.9)$ & $67(6.9 \%)$ & $88(9.1 \%)$ & +21 \\
Overweight $(25.0-29.9)$ & $243(25.1 \%)$ & $270(27.9 \%)$ & +27 \\
Obesity class I (30.0 - 34.9) & $355(36.6 \%)$ & $356(36.7 \%)$ & +1 \\
Obesity class II $(35.0-39.9)$ & $207(21.4 \%)$ & $170(17.5 \%)$ & -37 \\
Extreme obesity (class III) (equal or more than 40.0$)$ & $93(9.6 \%)$ & $80(8.3 \%)$ & -13 \\
Total & $969(100 \%)$ & $969(100 \%)$ & 0.0 \\
P value & & $<0.001$ & \\
\hline
\end{tabular}

${ }^{*}$ McNemar-Bowker test was applied.

Table 4. Numbers and proportions of patients of the two genders stratified based the WC cut-off points and their WC measurements before and after the program.

\begin{tabular}{|c|c|c|c|}
\hline Waist circumference & $\begin{array}{c}\text { Session } 1 \\
\text { No. \& (\%) }\end{array}$ & $\begin{array}{c}\text { Session } 8 \\
\text { No. \& (\%) }\end{array}$ & $\begin{array}{c}\text { Change } \\
\text { No. \& (\%) }\end{array}$ \\
\hline WC at Risk ( for both sex) & $786(81.1 \%)$ & $761(78.5 \%)$ & $-25(-2.6 \%)$ \\
\hline Normal WC (for both sex) & $183(18.9 \%)$ & $208(21.5 \%)$ & $+25(+2.6 \%)$ \\
\hline Total & $969(100)$ & $969(100)$ & 0.0 \\
\hline $\mathrm{P}$ value* & & $<0.001$ & \\
\hline
\end{tabular}

${ }^{*}$ McNemartest was applied.

the cut-off point as shown in Table 5. The number of participants who had systolic and diastolic readings of $<140$ and $<90$ respectively has increased at the end of the program, whereas the numbers of those with risky systolic and diastolic readings have decreased.

A significant change in the average $\mathrm{HbAlc}$ value has be observed after implementing the program. The average $\mathrm{HbAlc}$ value has decreased from $8.5 \pm$ 
Table 5. BP categories before and after the program based on the cut-off point and related risk.

\begin{tabular}{ccccc}
\hline blood pressure categories & $\begin{array}{c}\text { Session 1 } \\
\text { No. \& (\%) }\end{array}$ & $\begin{array}{c}\text { Session } 8 \\
\text { No. \& }(\%)\end{array}$ & $\begin{array}{c}\text { Change } \\
\text { No. \& }(\%)\end{array}$ & P value $^{*}$ \\
\hline Systolic not at risk $(<140 \mathrm{mmHg})$ & $735(75.9 \%)$ & $824(85.0 \%)$ & $+89(+9.2 \%)$ & \\
Systolic at risk $(\geq 140 \mathrm{mmHg})$ & $234(24.1 \%)$ & $145(15.0 \%)$ & $-89(-9.2 \%)$ & $<0.001$ \\
Total & $969(100 \%)$ & $969(100 \%)$ & 0.0 & \\
Diastolic not at risk $(<90 \mathrm{mmHg})$ & $823(84.9 \%)$ & $909(93.8 \%)$ & $+86(+8.9 \%)$ & \\
Diastolic at risk $(\geq 90 \mathrm{mmHg})$ & $146(15.1 \%)$ & $60(6.2 \%)$ & $-86(-8.9 \%)$ & $<0.001$ \\
Total & $969(100 \%)$ & $969(100 \%)$ & 0.0 & \\
\hline
\end{tabular}

${ }^{*}$ McNemartest was applied.

1.9 to $7.9 \pm 1.8$, indicating an overall drop of $0.6 \pm 1.2$ (Table 2). Of all the 969 patients, $27.1 \%$ had a reduction of $\geq 1.0 \%$ in their HbAlc readings. Table 6 shows the numbers of patients classified as "controlled" or "uncontrolled" using the HbAlc cut-off point determine by the American Diabetes association (ADA); patients with $\mathrm{HbA} 1 \mathrm{c}$ readings $<7.0 \%$ are considered to be controlled, while those with values $\geq 7.0 \%$ are considered at risk for diabetes complication [24].

\section{Discussion}

The purpose of this study was to examine the impact of a social network based diabetes education program, called UNRWA-MCI program, which is based on a novel "Microclinic" model of MCI. This program is designed to raise the awareness of diabetic patients about their condition, to help them modify their lifestyle to be healthier, to help them in self-management of their condition, and to empower them and their social networks. Overall, participants in the four fields of UNRWA operations showed improvements in their body measurements and HbA1c values after the intervention.

Globally, many efforts towards making healthy lifestyle changes for patients with diabetes have been exerted. In addition, many studies have shown that patients with diabetes do not adequately manage their disease, even after receiving education about diabetes care [26] [27]. Moreover, different studies have shown a significant relationship between health and social support, where people who receive higher levels of social support have better health. Diabetes disturbs daily performance and social activities of diabetic patients, changes their capability to perform normal roles and responsibilities, and creates new roles for them. In a world where social relationships with friends and family members are week, the need for social support becomes increasingly very important. Social support affects the control of diabetes through two mechanisms: 1) direct effect via behaviors related to health, such as encouraging healthy lifestyle behaviors, and 2) moderating effect which helps in the moderation of acute and chronic nervous 
Table 6. Numbers of patients who have controlled and uncontrolled diabetes conditions, based on the ADA cut-off point for $\mathrm{HbAlc}$, before and after the program.

\begin{tabular}{cccc}
\hline HBAlc categories & $\begin{array}{c}\text { Session 1 } \\
\text { No. \& }(\%)\end{array}$ & $\begin{array}{c}\text { Session } 8 \\
\text { No. \& }(\%)\end{array}$ & $\begin{array}{c}\text { Change } \\
\text { No. \& (\%) }\end{array}$ \\
\hline Controlled (HBA1c $<7 \%)$ & $232(23.9 \%)$ & $316(32.6 \%)$ & $+84(+8.7 \%)$ \\
Un controlled (HBA1c $\geq 7 \%)$ & $737(76.1 \%)$ & $653(67.4 \%)$ & $-84(-8.7 \%)$ \\
Total & $969(100 \%)$ & $969(100 \%)$ & 0.0 \\
P value $^{*}$ & $<0.001$ & \\
\hline
\end{tabular}

${ }^{*}$ McNemartest was applied.

pressure on health and increase of compatibility with the nervous pressure of the diabetes disease [17].

Social support networks may mediate the impacts of economic and environmental disadvantages by promoting increased access to social capital, with a resulting increase in self-efficacy behaviors. Social support has been examined in numerous forms, as it relates to the facilitation and hindrance of patients' self-management of chronic diseases such as diabetes. However, social support is a complex concept which corresponds to the multiple social networks (familial, occupational, community-based, institutional, etc.) surrounding an individual patient that exert positive and negative influences on a patient's ability to self-manage [28] [29] [30].

In order to address challenges of diabetes care at UNRWA health centers, the Agency had performed two clinical audits. The goal of both was to acquire information on current diabetes care at UNRWA health centers. During UNRWA's clinical audit in 2012, it was revealed that over $90.0 \%$ of patients with DM were overweight or obese (the majority (64.0\%) being obese). Based on UNRWA's clinical audit recommendations, it has been decided to take several actions such as: developing a comprehensive package for healthy lifestyle support activities that can be implemented in health centers with virtually no additional cost, and implementing a systematic way for the involvement of nurses and paramedical staff in diabetes care delivery to be more proactive and to lead to improved skills to help patients' health promotion, education and adherence [8] [13].

In response to the 2012 clinical audit results, in 2013, UNRWA Health Program embarked on a campaign titled "Life is Sweeter with Less Sugar" to assist both patients and staff in changing their attitudes and behaviors in order to prevent and control DM. Thirty HCs conducted weekly group educational sessions, healthy cooking, and exercise for six months. Body measurements, blood tests and patients' attendance data was collected on monthly basis. At the end of the campaign, $17.0 \%$ of the participants lost $\geq 5.0 \%$ of their weight, $19.0 \%$ lost between $3.0 \%-5.0 \%$ and $29.0 \%$ lost $1.0 \%-3.0 \%$ of their weight. Significant reduction was observed in the number of patients with high-risk waist circumference $(p<0.001)$. In addition, significant improvements were observed in blood sugar and cholesterol levels [15]. 
In order to sustain and improve more the healthy lifestyle awareness, practices and health care management of DM among Palestine refugees, UNRWA started, in collaboration with Microclinic International (MCI) a joint project, funded by WDF, to address diabetes type 2 epidemic among Palestine refugees. Launched in July 2015, the UNRWA-MCI program was implemented as an innovative program designed to expand awareness about diabetes care, including knowledge, attitudes and practices, among diabetic patients registered at UNRWA's HCs and willing to participate in this program.

The MCI's Social Network (MSN) model, that has been impelemtened at UNRWA's HCs, was formally evaluated via RCT methodology in several settings. After 10-month randomized controlled trial in Bell County, Kentucky, the MSN intervention was evaluated. TheMSN intervention group showed decreased body weight of $-6.52 \mathrm{lbs}$ (95\% CI: -8.57 to -4.47 ) compared to the control $(\mathrm{p}<0.001)$ and the central adiposity has improved substantially, with a waist circumference net change of -1.24 inches $(-1.85$ to $-0.63 ; \mathrm{p}<0.001)$. Furthermore, MSN participants notably lowered systolic blood pressure by -6.59 $\mathrm{mm} \mathrm{Hg}(-12.7$ to $-0.48 ; \mathrm{p}=0.03)$. These results indicate that theMCI Social Networklifestyle intervention may be effective for weight loss management [21].

The MSN intervention was also implementedin Jordan, and the effectiveness of such a socialnetwork program for sustaining long-term health gainswas assessed inpatients with diabetes or prediabetes that have been enrolled in the 4-month MCI program and followed up for 2 years. 216 (69.6\%) patients out of 315 participants returned for the 24-month follow-up. It was shown that participants maintained an average weight loss of $-1.60 \mathrm{Kg}(-2.67$ to $-0.54 ; \mathrm{p}=$ $0.003)$ after 2 years from baseline, -0.43 ( -0.82 to -0.05$)$ reduction in BMI, and $-0.97 \%(-1.12$ to $-0.81 ; \mathrm{p}<0.0001)$ reduction in HbA1c. Such a social network based intervention may be a promising tool to propagate healthy behaviors for diabetes and obesity prevention throughout a community [14].

Other studies were conducted in low-income countries toinvestigate the impact of social support in diabetes care. For example, an evaluation of the effectiveness of peer-led self-management education in improving glycemic control in patients with type 2 diabetes was conducted inMali. As they have conducted an open-label randomised controlled trial with 151 diabetic patients, treated at the diabetes consultation units in two health centers, in which one group was allocated to peer-led structured patient education $(\mathrm{n}=76)$ and the other group was allocated to conventional care alone. The intervention resulted in improvements in the glycaemic control and anthropometric parameters, including $1.05 \%$ reduction in average $\mathrm{HbAlc}$ levels and $1.65 \mathrm{Kg} / \mathrm{m}^{2}$ reduction in the average BMI readings [31]. In another study, Koetsenruijter and his colleagues have conducted a cross-sectional studyto explore which aspects of social networks are related to self-management capabilities and if these networks have the potential to reduce the adverse health effects of deprivation for type 2 diabetes patients in six European countries. The association of self-management 
capabilities with informational support was especially strong in the low education group, whereas the association with emotional support was stronger in the high education group. The authors concluded that the informational support may therefore provide a possibility to reduce the adverse impact of low education on self-management capabilities [32].

Comparing these result with UNRWA's and MCI joint project, similar improvements wereseen after 2 years of implementing the project. For example, there was an average body weight loss of $-1.9 \pm 2.6$, and an overall BMI category shift, especially in the obese class II category and normal weight, as shown in Table 3 earlier. In addition, the average WCdecreased from $103.6( \pm 15.3)$ to $101.9( \pm 14.7)$, with an overall decrease in the number of patients in the high risk WC category. Concerning the HbAlc control levels, $8.7 \%$ more patients had their HbA1c level become controlled (from 23.9\% to $32.6 \%$ ). It is worth mentioning that the control rates of patients included in the clinical audits during 2012 and 2015 were $28.3 \%$ and $25.1 \%$ respectively.

While to our knowledge there have been no other published studies evaluating a similar social support diabetes education program in refugee context population, there have been recent systematic reviews highlighting the lack of literature on NCD interventions in humanitarian crisis settings. For instance, a 2017 review of public health interventions for humanitarian crisis settings, found only two out of 345 studies that addressed NCDs in refugee settings [33]. Another systematic review looking only at NCD interventions for humanitarian crisis settings, had a final study sample of eight published studies; three involved Palestine refugee patients, and evaluated an electronic medical record intervention [34]. None of the included studies utilized a social network based intervention. These results highlight the extremely limited quantity and quality of evidence on NCD interventions in this setting, and the importance of studies like this one.

Our study has several important strengths. This strategy highlighted many of the barriers to healthcare services within the context of refugee camp settings. The MSN model was culturally tailored to suit Palestine refugee community settings. In addition, it did not only involve patients' social networks, but also has engaged local nurses and healthcare workers in implementing the program. A recent review evaluating the status of the diabetes epidemic among Palestinians, identified internal and external barriers to NCD care; it noted that internal factors (such as psychosocial and cultural attitudes, and interpersonal factors) were the most difficult obstacles to overcome, which is why culturally competent programs are key to effectively combatting NCDs, especially among Palestine refugees [19]. Furthermore, measurements were taken in a clinical setting by medical professionals, which improved the accuracy and reliability of our data. We also observed trends consistent across all measures, and at HCs in all locations, and our results were consistent with previous MSN intervention studies.

Our study also had some limitations. We only recruited patients from the largest UNRWA clinics at each location, only included registered Palestine refu- 
gee patients registered at these HCs in the study, and the study population mostly consisted of women. We also did not have a control group, which limits our ability to make conclusions on the effectiveness of the MSN intervention. Future studies should incorporate more male participants, and develop a study strategy to minimize bias in settings where randomized controlled studies are not feasible or ethical.

The MSN model complements existing UNRWA strategies to combat NCDs, and helps improve their impact involving patients' social networks to support positive behavior change and spread positive lifestyle behaviors. The results of this study indicate that the MSN diabetes education model could be an effective strategy to address diabetes and related risk factors among Palestine refugees in a camp setting, and warrants further evaluation via a Randomized Clinical Trail.

\section{Funding}

The project has been funded by World Diabetes Foundation (WDF) through Microclinic International (MCI) and implemented by UNRWA in close coordination with MCI.

\section{Conflicts of Interest}

The authors have no conflicts of interest to declare.

\section{References}

[1] Sabatinelli, G., Pace-Shanklin, S., Riccardo, F. and Shahin, Y. (2009) Palestinian Refugees outside the Occupied Palestinian Territory. The Lancet, 373, S0140. https://doi.org/10.1016/S0140-6736(09)60101-X

[2] Giacaman, R., Khatib, R., Shabaneh, L., Ramlawi, A., Sabri, B., Sabatinelli, G., Khawaja, M. and Laurance, T. (2009) Health Status and Health Services in the Occupied Palestinian Territory. The Lancet, 373, 837-849. https://doi.org/10.1016/S0140-6736(09)60107-0

[3] Husseini, A., Abu-Rmeileh, N. and Mikki, N. (2009) Cardiovascular Diseases, Diabetes Mellitus, and Cancer in the Occupied Palestinian Territory. The Lancet, 9, 1041-1049. https://doi.org/10.1016/S0140-6736(09)60109-4

[4] United Nations Relief and Works Agency. (2017) Annual Report of the Department of Health.

https://www.unrwa.org/sites/default/files/content/resources/health_programme_an nual_report_2017.pdf

[5] Shahin, Y., Kapur, A. and Seita, A. (2015) Diabetes Care in Refugee Camps: The experience of UNRWA.Diabetes Research and Clinical Practice, 108, 1-6. https://doi.org/10.1016/j.diabres.2015.01.035

[6] Ata Abu Obaid, H. (2017) Diabetes Mellitius: A Major Public Health Problem in Palestine. European Journal of Pharmaceutical and Medical Research, 4, 801-808.

[7] Khader, A., Ballout, G., Shahin, Y., Hababeh, M., Farajallah, L., Zeidan, W., Abu-Zayed, I., Kochi, A., Harries, A., Zachariah, R., Kapur, A., Shaikh, I. and Seita, A. (2014) Diabetes Mellitus and Treatment Outcomes in Palestine Refugees in UNRWA Primary Health Care Clinics in Jordan. Public Health Action, 3, 259-264. https://doi.org/10.5588/pha.13.0083 
[8] Shahin, Y., Kapur, A., Khader, A., Zeidan, W., Harries, A., Nerup, J. and Seita, A. (2015) Clinical Audit on the Provision of Diabetes Care in the Primary Care Setting by United Nations Relief and Works Agency for Palestine Refugees in the Near East. Journal of Diabetes Mellitus, 5, 12-20. https://doi.org/10.4236/jdm.2015.51002

[9] Slama, S., Kim, H., Roglic, G., Boulle, P., Hering, H., Varghese, C., Rasheed, S. and Tonelli, M. (2017) Care of Non-Communicable Diseases in Emergencies. The Lancet, 389, 326-330.https://doi.org/10.1016/S0140-6736(16)31404-0

[10] Perone, S., Martinez, E., du Mortier, S., Rossi, R., Pahud, M., Urbaniak, V., Chappuis, F., Hagon, O., Bausch, F. and Beran, D. (2017) Non-Communicable Diseases in Humanitarian Settings: Ten Essential Questions. Conflict and Health, 11, 17. https://doi.org/10.1186/s13031-017-0119-8

[11] Solberg, K. (2009) Pakistan's Refugee Crisis Raises Health Concerns. The Lancet, $373,3$.

[12] United Nations Relief and Works Agency. (2016) Annual Report of the Department of Health.

https://www.unrwa.org/sites/default/files/content/resources/2016_health_departme nt_annual_report.pdf

[13] UNRWA Clinical Audit. (2013).

https://www.unrwa.org/sites/default/files/final_dm_clinical_audit_report_-_small_s ize.pdf

[14] Zoughbie, D., Watson, K., Bui, N., Farraj, R., Prescott, M. and Ding, E. (2014) Long-Term Bodyweight and Glucose Management Effects of the Microclinic Social Network Health Behavioral Program in Amman, Jordan: 2-Year Results. The Lancet Global Health, 2, S19. https://doi.org/10.1016/S2214-109X(15)70041-0

[15] Abu Kishk, N., van den Berg, M., Seita, A., Zadian, W., Turki, Y. and Shahin, Y. (2015) Evaluation of the Diabetes Campaign for Palestine Refugees with Diabetes Mellitus Attending UNRWA Health Centers. International Journal of Food Science, Nutrition and Dietetics, 4, 246-252. https://doi.org/10.19070/2326-3350-1500044

[16] World Health Organization (2000) Obesity: Preventing and Managing the Global Epidemic. Report of a WHO Consultation, WHO Technical Report Series, 894.

[17] Rad, G., Bakht, L.A. and Mohebi, S. (2013) Importance of Social Support in Diabetes Care.Journal of Education and Health Promotion, 2, 62. https://doi.org/10.4103/2277-9531.120864

[18] Microclinic International (MCI) Website. http://microclinics.org/about/

[19] Zoughbie, D.E. (2009) Community-Based Diabetes Programme: The Microclinic Project. Eastern Mediterranean Health Journal, 15, 1021-1026.

https://doi.org/10.26719/2009.15.4.1021

[20] Rushakoff, J.A., Zoughbie, D.E., Bui, N., DeVito, K., Makarechi, L. and Kubo, H. (2017) Evaluation of Healthy2Go: A Country Store Transformation Project to Improve the Food Environment and Consumer Choices in Appalachian Kentucky. Preventive Medicine Reports, 7, 187-192.

https://doi.org/10.1016/j.pmedr.2017.06.009

[21] Ding, E., Watson, K., Bui, N., Makarechi, L., Lang, L., Prescott, M., Safford, S., Banerjee, D., Campbell, H., Rushakoff, J. and Zoughbie, D. (2013) Randomized Trial of Social Network Lifestyle Intervention for Obesity: Microclinic Intervention Results and 16-Month Follow-Up. Circulation, 128, 2704-2722.

[22] World Health Organization. (2011) Waist Circumference and Waist-Hip Ratio. Report of a WHO Expert Consultation, Geneva, 8-11 December 2008. 
[23] UNRWA Technical Instruction on Non Communicable Diseases 2009. https://goo.gl/aBpSZf

[24] Whelton, P.K., Carey, R.M., Aronow, W.S., Casey, D.E., Collins, K.J., et al. (2018) 2017 ACC/AHA/AAPA/ABC/ACPM/AGS/APhA/ASH/ASPC/NMA/PCNA Guideline for the Prevention, Detection, Evaluation, and Management of High Blood Pressure in Adults: A Report of the American College of Cardiology/American Heart Association Task Force on Clinical Practice Guidelines. Journal of the American College of Cardiology, 71, e127-e248.

[25] American Diabetes Association. (2017). Standards of Medical Care in Diabetes. The Journal of Clinical and Applied Research and Education, Diabetes Care, 40, Supplement 1 .

[26] Greenwood, D.A., Kramer, M.K., Hankins, A.I., Carol, A., Parise, A.F., et al. (2014) Adapting the Group Lifestyle Balance Program for Weight Management within a Large Health Care System Diabetes Education Program. American Association of Diabetes Educators, 40, 299. http://tde.sagepub.com/content/40/3/299 https://doi.org/10.1177/0145721714524281

[27] Rickhem, P.L., Todd, W., Weaver, L., Flader, J. and Kendall, D. (2002) Assessment of Group versus Individual Diabetes Education. A Randomized Study. Diabetes Care, 25, 269-274. https://doi.org/10.2337/diacare.25.2.269

[28] Vest, B.M., Kahn, L.S. and Danzo, A. (2013) Diabetes Self-Management in a Low-Income Population: Impacts of Social Support and Relationships with the Health Care System. Chronic Illness, 9, 145-155. https://doi.org/10.1177/1742395313475674

[29] Shaw, B.A., Gallant, M.P., Riley-Jacome, M., et al. (2006) Assessing Sources of Support for Diabetes Self-Care in Urban and Rural Underserved Communities. Journal of Community Health, 31, 393-412. https://doi.org/10.1007/s10900-006-9018-4

[30] Van Dam, H.A., van der Horst, F.G., Knoops, L., et al. (2005) Social Support in Diabetes: A Systematic Review of Controlled Intervention Studies. Patient Education and Counseling, 59, 1-12. https://doi.org/10.1016/j.pec.2004.11.001

[31] Debussche, X., BesancËon, S., Balcou-Debussche, M., Ferdynus, C., Delisle, H., Huiart, L., et al. (2018) Structured Peer-Led Diabetes Self-Management and Support in a Low-Income Country: The ST2EP Randomised Controlled Trial in Mali. PLoS ONE, 13, e0191262. https://doi.org/10.1371/journal.pone.0191262

[32] Koetsenruijter, J., et al. (2016) Social Support and Self-Management Capabilities in Diabetes Patients: An International Observational Study. Patient Education and Counseling, 99, 638-643.https://doi.org/10.1016/j.pec.2015.10.029

[33] Blanchet, K., Ramesh, A., Frison, S., Warren, E., Hossain, M., Smith, J., Knight, A., Post, N., Lewis, C., Woodward, A., Dahab, M., Ruby, A., Sistenich, V., Pantuliano, S. and Roberts, B. (2017) Evidence on Public Health Interventions in Humanitarian Crises. The Lancet, 390, 2287-2296. https://doi.org/10.1016/S0140-6736(16)30768-1

[34] Khader, A., Ballout, G., Shahin, Y., Hababeh, M., Farajallah, L., Zeidan, W., Abu-Zayed, I., Kochi, A., Harries, A., Zachariah, R., Kapur, A., Shaikh, I. and Seita, A. (2014) Treatment Outcomes in a Cohort of Palestine Refugees with Diabetes Mellitus Followed through Use of E-Health over 3 Years in Jordan. Tropical Medicine and International Health, 19, 219-223. https://doi.org/10.1111/tmi.12241 